\title{
Crossed Rhythmic Synaptic Input to Motoneurons during Selective Activation of the Contralateral Spinal Locomotor Network
}

\author{
Ole Kjaerulff and Ole Kiehn \\ Division of Neurophysiology, Department of Medical Physiology, The Panum Institute, University of Copenhagen, DK- \\ 2200 Copenhagen, Denmark
}

To investigate the cellular mechanisms underlying locomotorrelated left-right coordination, we monitored the crossed synaptic input to lumbar motoneurons during contralateral ventral root rhythmicity in the neonatal rat spinal cord in vitro. Using a longitudinal split-bath setup, one hemicord was kept in normal solution, whereas the contralateral hemicord was exposed to 5-HT and NMDA. With this approach, rhythmic bursting could be induced in the ventral roots on the agonist-exposed side, whereas the ventral roots on the agonist-free side remained silent. Intracellular recordings were made from L1-L3 motoneurons on the silent agonist-free side during rhythmic activity in the contralateral ventral roots. At the resting membrane potential, the typical crossed synaptic input was a rhythmic barrage of depolarizing IPSPs. This input modulated the frequency of spikes induced with depolarizing direct current by inhibiting firing in phase with the contralateral bursts. Intracellular chlo- ride loading increased the amplitude of the IPSPS, suggesting that they were chloride-dependent. Strychnine but not bicuculline generally blocked the rhythmic inhibitory input when added to the agonist-free side during contralateral rhythmicity. APV and CNQX on the agonist-free side abolished the rhythmic inhibitory input in most motoneurons but not in all.

We suggest that rat spinal motoneurons receive a mainly glycinergic rhythmic inhibition from the contralateral half of the locomotor network. Unlike in simpler vertebrates, the crossed inhibition often appears to be at least disynaptic, involving inhibitory premotor neurons located on the same side as the receiving motoneurons. These premotor neurons are rhythmically excited via a crossed pathway that depends on glutamatergic transmission.

Key words: spinal cord; 5-HT; central pattern generator; rhythmicity; NMDA; glycine
Vertebrates possess a spinal neuronal network, called the central pattern generator (CPG), that is able to exert a detailed control of locomotor movements (Grillner, 1981; Rossignol, 1996). One of the important tasks of the spinal CPG is to maintain the proper left-right coordination of locomotor activity. Experimentally derived models of the spinal network organizing locomotion have been established in two relatively simple vertebrates, the lamprey (Wallén et al., 1992) and the Xenopus embryo (Dale, 1995; Roberts et al., 1995). One may ask to what extent these models, which are based on animals that locomote using bodily movements, are relevant for understanding the spinal control of left-right coordination of limb movements in vertebrates, including mammals.

One mammal in which left-right coordination of limb movements has been studied in some detail is the neonatal rat. Although rats younger than postnatal day 12 are unable to walk because of postural weakness (Westerga and Gramsbergen, 1990), their interlimb coordination has been studied in vivo, because they can already swim a few hours after birth (Bekoff and Trainer, 1979; Cazalets et al., 1990). Work in the isolated spinal cord of the neonatal rat (Kudo and Yamada, 1987; Smith and Feldman, 1987) has mainly examined the pharmacology and the gross anatomy of connections coordinating alternating or synchronized bilateral rhythmic activity (Cazalets et al., 1995; Bracci

Received June 30, 1997; revised Sept. 26, 1997; accepted Sept 29, 1997.

This work was supported by the NOVO Foundation and the Danish Medical Research Council. O.K. is a Hallas Møller Associate Professor. Dr. Bruce Johnson helped improve the English of this manuscript.

Correspondence should be addressed to Dr. Ole Kiehn, Division of Neurophysiology, Department of Medical Physiology, The Panum Institute, Blegdamsvej 3, DK-2200 Copenhagen, Denmark.

Copyright (C) 1997 Society for Neuroscience $0270-6474 / 97 / 179433-15 \$ 05.00 / 0$ et al., 1996, Kjaerulff and Kiehn, 1996; Cowley and Schmidt, 1997, Kremer and Lev-Tov, 1997) and the ontogeny of left-right coordination (Bekoff and Lau, 1980; Ozaki et al., 1996). Although these studies have provided valuable information, much remains to be clarified about the cellular mechanisms underlying leftright coordination of locomotor-related rhythmicity in the neonatal rat. Therefore, we have developed a longitudinal split-bath preparation, in which one-half of the spinal CPG can be preferentially activated by exposing the corresponding hemicord to rhythm-inducing agonists while keeping the opposite hemicord in normal solution. By recording intracellularly on the agonist-free side, the crossed synaptic input received from the agonistexposed active side can be monitored. The pharmacology of this input can be studied by the use of specific antagonists, restricted to the agonist-free compartment to interfere minimally with ongoing rhythmicity in the agonist-containing compartment. The split-bath technique has been used previously in the rat to characterize the synaptic input from active rostral rhythmic networks to caudal motoneurons (Cazalets et al., 1996) and in the lamprey for a similar purpose (Dale, 1986).

In this study, we have focused on motoneurons, presently the only readily identifiable neuronal class known to be involved in locomotor-related activity in the neonatal rat. Our findings suggest that during spinal locomotor activity, lumbar motoneurons controlling flexor-related muscular activity receive rhythmic inhibition from the contralateral half of the rhythm-generating network. The crossed inhibitory input is mainly glycinergic and appears to depend substantially on transmission through polysynaptic pathways. We also present preliminary evidence of a crossed 
excitatory rhythmic input to a smaller population of flexor-related motoneurons.

\section{MATERIALS AND METHODS}

Dissection. One-day-old Wistar rats were used. Spinal cord pieces, typically consisting of the T10-L4 segments, were isolated as described previously (Kjaerulff and Kiehn, 1996) and continuously superfused with normal solution containing (in mM): $128 \mathrm{NaCl}, 4.69 \mathrm{KCl}, 25 \mathrm{NaHCO}_{3}$, $1.18 \mathrm{KH}_{2} \mathrm{PO}_{4}, 1.25 \mathrm{MgSO}_{4}, 2.52 \mathrm{CaCl}_{2}$, and 22 glucose, aerated with $5 \%$ $\mathrm{CO}_{2}$ in $\mathrm{O}_{2}$. Experiments were performed at room temperature.

Partitioning of the experimental chamber. To permit selective unilateral drug exposure of the spinal cord, the cord was included in a barrier built to separate two independently perfused experimental chambers, one on each side of the cord (Fig. 1A). The long edge of a rectangular plastic bar was glued with Histoacryl (Braun, Melsungen, Germany) to the dorsal midline of the cord, which was then fixed with the ventral surface upward by pressing the bar into a cushion of soft gum (Plastik; Platignum, Royston, UK) covered with petroleum jelly. Subsequently, a second thinner plastic bar was glued to the ventral midline of the cord, using a minimum of glue. The glue was allowed to slightly harden before adhering to the tissue, to prevent excessive lateral spreading. The two to three rostral-most thoracic segments and the caudal-most lumbar segment were covered with petroleum jelly, leaving approximately T13-L3 exposed to the two superfusing solutions. The separation of the two chambers was completed with petroleum jelly. The presence of a watertight seal between the preparation and the rest of the barrier was confirmed either by adding phenol red (phenolsulfonphtalein; 1-2 mg/100 ml; Sigma, St. Louis, MO) to the perfusing solution of one chamber and inspecting for leakage to the contralateral chamber, or, more often, by testing whether a different fluid level in the two chambers could be maintained during a pause in the perfusion.

Unilateral rhythmic ventral root activity was induced by adding 5 -HT and NMDA in combination to one compartment only while perfusing the contralateral compartment with normal solution (see Results). Ideally, only the locomotor network in the hemicord showing ventral root rhythmicity was exposed to the rhythm-inducing agonists. However, in principle, 5-HT and NMDA could have diff used through the preparation from the agonist-exposed hemicord to the contralateral hemicord, perhaps leading to a weak activation of the locomotor network on that side. To investigate the possibility of such crossed diffusion, we tried in two preparations to use methylene blue $(\sim 1 \%)$ as an indicator of the distribution of 5-HT and NMDA in the tissue. Methylene blue was added to one compartment for $\sim 1 \mathrm{hr}$, before the preparation was fixed in $4 \%$ paraformaldehyde and cut transversally to inspect for leakage to the contralateral hemicord. We found that, after the $\sim 1 \mathrm{hr}$ waiting period, methylene blue was largely restricted to the superficial layers of the white matter on the side of the cord to which it had been added. In contrast, in preparations showing unilateral ventral root rhythmicity, 5-HT and NMDA already reached the gray matter on the agonist-exposed side $<15$ min after being added to the bath, because this was the observed maximal delay for the appearance of unilateral rhythm. Thus, in our hands methylene blue was not useful as an indicator substance for 5-HT and NMDA, and the possibility of crossed diff usion was therefore not directly excluded with this method. However, we will argue later (see Discussion) that the hemicord superfused with normal solution was exposed to very low concentrations of 5-HT and NMDA because of crossed diffusion, and that the locomotor network in that hemicord was unlikely to have been strongly activated during contralateral rhythmicity.

Recordings. Ventral root activity was recorded with suction electrodes and filtered (bandpass, $100 \mathrm{~Hz}-10 \mathrm{kHz}$ ). Intracellular current-clamp recordings were made with sharp electrodes pulled from borosilicate glass (GC100F-7.5, $1.0 \mathrm{~mm}$ outer diameter; Clark Electromedical Instruments, Pangbourne, UK). Some electrodes were filled with potassium acetate alone, whereas others (low-chloride electrodes) were filled with potassium acetate in combination with a low (maximum $0.5 \mathrm{M}$ ) potassium chloride concentration. High-chloride electrodes, containing at least 1.0 M potassium chloride, were also used. The total electrolyte concentration was $1.0-2.0 \mathrm{M}$ in all electrodes. The electrode resistance was $\sim 50-150$ $\mathrm{M} \Omega$. The current-voltage relation of the electrodes was strongly nonlinear, reducing the reliability of the measured membrane potential when passing current through the electrodes. Therefore, the membrane potential was determined only during zero current injection, whereas otherwise we report the direct current (DC) used to depolarize or hyperpolarize the motoneurons.

To record from motoneurons, the electrode was lowered into the rostral part of the ventral root exit area. Cells were identified as motoneurons when an antidromic spike with a sharp onset and a clear latency could be evoked by stimulating the ventral roots through the suction electrodes (stimulus duration, $0.2 \mathrm{msec}$; amplitude, $<30 \mu \mathrm{A}$; typically $10-20 \mu \mathrm{A}$ was sufficient). In the large majority of motoneurons defined in this way, an orthodromic spike could in addition be recorded in the ventral root, when the cell was depolarized beyond the firing threshold. Intracellular recordings were made in bridge mode using an Axoclamp 2B amplifier (Axon Instruments) and stored on a digital tape recorder (Biological DTR 1800) together with the ventral root recordings.

\section{Data analysis}

Ventral root recordings. For comparison of the frequency and amplitude of unilateral and bilateral rhythmic bursts, ventral root recordings were sampled $(10 \mathrm{kHz})$ on a personal computer (Digital Celebris GL 5133 ${ }^{\text {st }}$ ) supplied with a digitizer board (Digidata 1200) and acquisition software (Axoscope 1.1), both from Axon Instruments. The recordings were rectified and digitally smoothed with an exponential function, before determining the cycle period and modulation amplitude as indicated in Figure $1 C$

Cross-correlation analysis. A statistical criterion was used to determine whether the membrane potential $\left(V_{\mathrm{m}}\right)$ of a given motoneuron showed a rhythmic modulation phase-coupled to the contralateral ventral root bursts [i.e., a contralateral-rhythm-related potential (CRRP); see Results] or whether fluctuations in $V_{\mathrm{m}}$ were not systematically related to contralateral rhythmicity. An interval of the intracellular recording and the concurrent contralateral ventral root recording, including 8-20 cycles of regular bursting, were sampled off-line. The ventral root recording was rectified, whereas the intracellular recording was digitally high-passfiltered at $0.1 \mathrm{~Hz}$ to remove slow trends in $V_{\mathrm{m}}$ (e.g., electrode drift). The number of samples in both traces was reduced with a minimum-maximum algorithm to $\sim 400$ per cycle, and the traces were digitally smoothed (50 points moving average). The remaining part of the procedure is illustrated in Figure $1 C$. For each cycle, we determined the time point corresponding to the maximum amplitude $\left(V R_{\max }\right)$ of the rectified and smoothed ventral root recording and the time point corresponding to the minimum ventral root amplitude $\left(V R_{\min }\right)$. These time points are termed $t_{\mathrm{VRmax}}$ and $t_{\mathrm{VRmin}}$, respectively. Switching to the intracellular recording, we then measured $\Delta V_{\mathrm{m}}$ (root), which is the difference between $V_{\mathrm{m}}$ at $t_{\mathrm{VR} \max }$ and $V_{\mathrm{m}}$ at $t_{\mathrm{VRmin}}$. The magnitude of $\Delta V_{\mathrm{m}}$ (root) expresses the degree of correlation between the motoneuron membrane potential and the amplitude of the contralateral ventral root output. The ventral root amplitude and the membrane potential were considered to be significantly correlated if $\Delta V_{\mathrm{m}}$ (root) was significantly different from zero when averaged over all cycles (paired $t$ test; $5 \%$ level of statistical significance). $\Delta V_{\mathrm{m}}$ (root) is positive if this correlation is positive (ventral root and motoneuron in phase with each other) and negative if the correlation is negative (ventral root and motoneuron out of phase with each other). In Results, instead of using the term correlation, we state that a significant CRRP was present in the motoneuron when $\Delta V_{\mathrm{m}}$ (root) differed significantly from zero.

Induction of rhythmic activity. Unilateral ventral root rhythmicity was induced with a combination of NMDA [concentration, $6.7 \pm 0.9 \mu \mathrm{M}$ (mean $\pm \mathrm{SD}$ ), range 5.0-7.5 $\mu \mathrm{M}]$ and 5-hydroxytryptamine (5-HT/serotonin; $8.0 \pm 3.0 \mu \mathrm{M}$; range, $5.0-15.0 \mu \mathrm{M})$, both from Sigma. In each experiment, we used NMDA and 5-HT concentrations close to the minimum concentrations necessary for activating the rhythm-generating networks (i.e., the threshold concentrations). Thus, we first tried concentrations in the lower end of the ranges specified here. These concentrations were increased to higher concentrations within the specified ranges only if necessary to obtain sustained regular rhythmic activity.

In some experiments, we quantitated the characteristics of both unilateral and bilateral rhythmic activity in the same preparation. In these experiments, the same 5-HT and NMDA concentrations as those used to induce unilateral rhythm were used to induced bilateral rhythm.

Antagonists. The following receptor antagonists were used: strychnine $(1-10 \mu \mathrm{M})$ from Sigma; and bicuculline (10-15 $\mu \mathrm{M})$, 6-cyano-7nitroquinoxaline-2,3-dione (CNQX; 2-10 $\mu \mathrm{M})$, and D-(-)-2-amino-5phosphonopentanoic acid (APV; $10-80 \mu \mathrm{M})$ from Research Biochemicals (Natick, MA). 
A

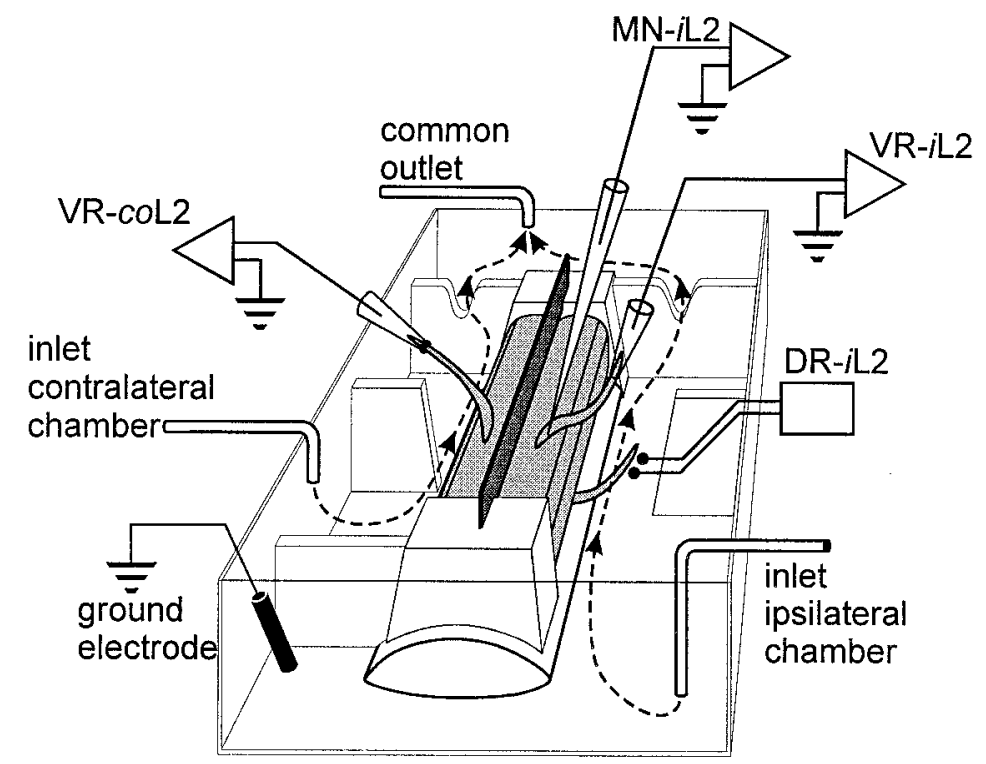

$\mathrm{B}$

\section{C}

VR-ilL2
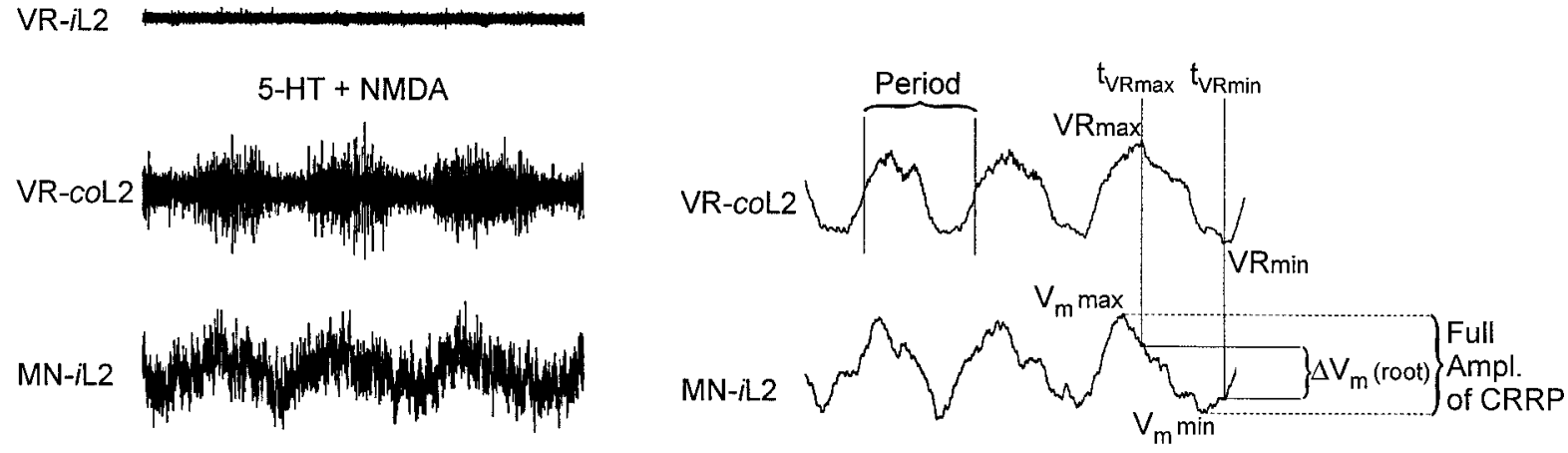

MN-iL2

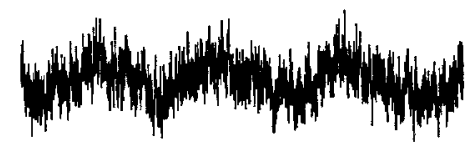

$\frac{5 \mathrm{mV}}{2 \mathrm{~s}}$

Figure 1. A, Schematic drawing of the split-bath preparation. The spinal cord (6-8 segments; light gray), placed with the ventral side upward, formed part of a barrier separating two independently perfused compartments. In addition to the spinal cord itself, a ventral plastic bar (dark gray), a dorsal bar (not visible) fixed on a base of gum, and petroleum jelly walls separated the two compartments. The intracellular recording from the motoneuron ( $M N-i L 2)$, and recordings from the ipsilateral $(V R-i L 2)$ and contralateral ventral roots $(V R-c o L 2)$ are shown. Typically, recordings were done in the L2 segment, as indicated. The ipsilateral dorsal root, arranged for stimulation, is also shown (DR-iL2), whereas the remaining roots are omitted for clarity. $B$, Ventral root recordings and intracellular recordings obtained during the addition of $7.0 \mu \mathrm{M} 5$-HT and $15.0 \mu \mathrm{M}$ NMDA to the compartment opposite from the intracellular recording compartment. After drug application, rhythmic bursts appeared on the agonist-exposed side (VR-coL2, middle trace). In contrast, in the intracellular recording compartment perfused with normal solution, the ventral roots remained silent (VR-iL2, top trace). Although no ventral root activity was observed on the agonist-free side, a rhythmic depolarization of the motoneuron membrane potential appeared on that side $(M N-i L 2$, bottom trace). This depolarization, called the iCRRP (see Results), was phase-locked to the rhythmic ventral root bursts on the contralateral, agonist-exposed side. In this and subsequent figures, the ventral root recordings from the two sides are shown with the same amplification. The microelectrode contained $0.5 \mathrm{M}$ potassium acetate and $0.5 \mathrm{M} \mathrm{KCl} C$, Quantitation of the CRRP and of the associated contralateral ventral root activity. The two bottom traces in $B$ are shown again after rectification and smoothing. The measurement of the cycle period, halfway between the trough and peak amplitudes of the ventral root output, is shown in the contralateral ventral root recording (top trace). The time points, $t_{V R \max }$ and $t_{V R \min }$, corresponding to the peak (VRmax) and trough (VRmin) amplitudes, respectively, of the ventral root output, were used to determine where to measure $\Delta V_{\mathrm{m}}$ (root) in the intracellular recording (bottom trace). The zero reference used when measuring $V R m a x$ and VRmin is omitted for clarity. Because $V R \max$ and $V R$ min rarely coincided precisely with the maxima and minima of the CRRP, $\Delta V_{\mathrm{m}}($ root) was generally smaller than the full CRRP amplitude (also indicated on the bottom trace). $\Delta V_{\mathrm{m}}$ (root) is used in Figures 4 and 7 as a measure of the CRRP amplitude, because determining the full CRRP amplitude could be subjective in cells with a small CRRP, whereas determining $\Delta V_{\mathrm{m}}$ (root) was always unequivocal. 
A

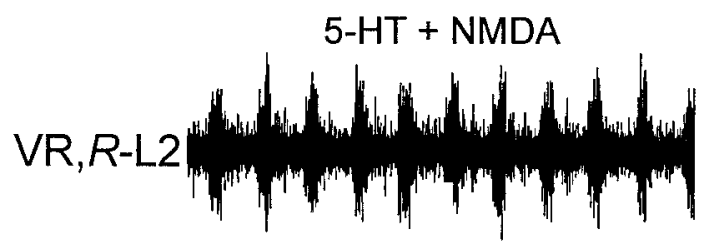

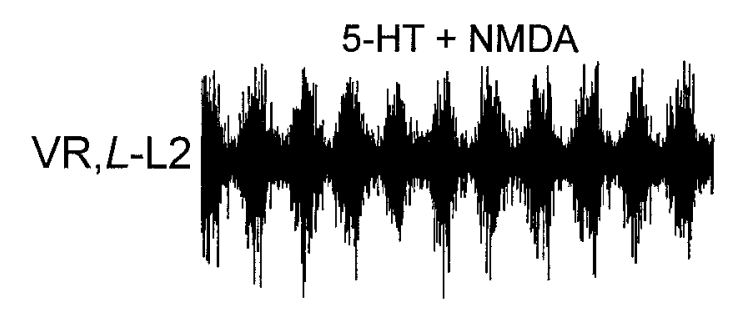

C

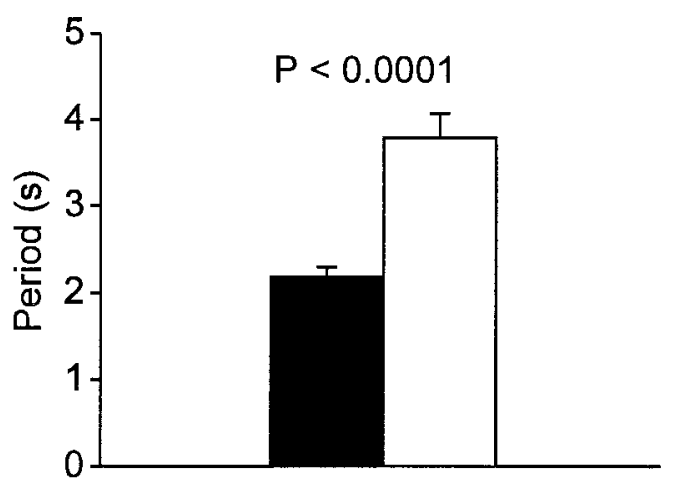

B

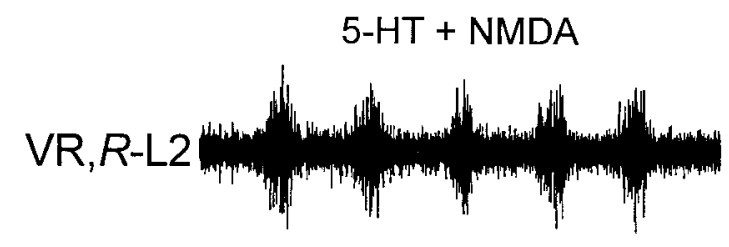

VR,L-L2
$5 s$

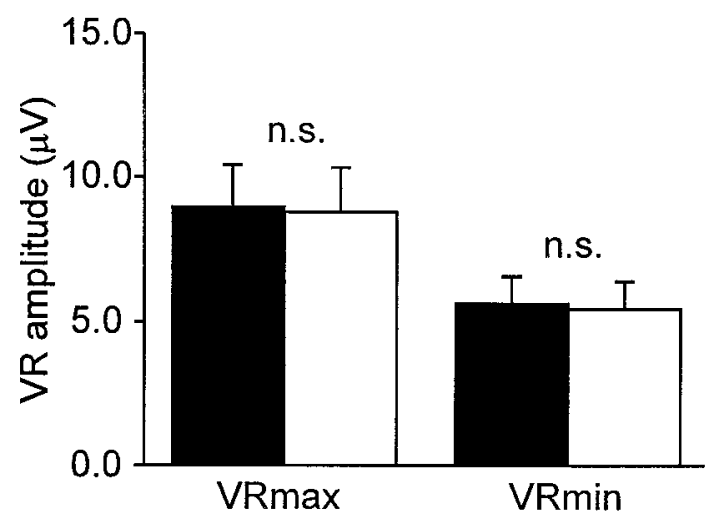

\section{Bilateral rhytmic activity}

\section{Unilateral rhythmic activity}

Figure 2. Frequency and amplitude of unilateral and bilateral rhythmic ventral root activity. $A$, Bilateral rhythmic ventral root activity induced by exposing both sides of the cord to $5.5 \mu \mathrm{M} 5-\mathrm{HT}$ and $5.5 \mu \mathrm{M}$ NMDA. $B$, Unilateral rhythmic ventral root activity in the same preparation, induced by adding 5-HT and NMDA to the compartment on the right side only (same concentrations as in $A$ ) and keeping the left side in normal solution. $C$, $D$, Pooled data from 18 preparations. The cycle period $(C)$ and the peak (VRmax) and trough (VRmin) amplitudes of the low-pass-filtered ventral root potential $(D)$ are shown. Values are mean \pm SD. n.s., Not significant.

\section{RESULTS}

\section{Comparison of the frequency and amplitude of} bilateral and unilateral rhythmic ventral root activity

Figure $2 A$ shows bilateral rhythmic ventral root activity induced with a combination of 5-HT and NMDA added to the compartments on either side of the cord. The bursts in the L2 ventral roots on the two sides alternated, as is normally the case for 5-HT- and NMDA-induced rhythm (Sqalli-Houssaini et al., 1993; Kjaerulff et al., 1994; Kjaerulff and Kiehn, 1996). After bilateral washout of 5-HT and NMDA, these rhythm-inducing agonists were added to one compartment only, in the concentrations used to induce the bilateral rhythm, while keeping the contralateral side in normal solution. As a result, rhythmic ventral root activity developed on the agonist-exposed side, whereas the ventral roots on the agonist-free side remained silent (Fig. 2B). This shows that it is possible to obtain a specific activation of the rhythm-generating network in one hemicord, at least at the level of the ventral root output. Characteristically, the cycle period of the unilateral rhythmic activity $(3.4 \mathrm{sec})$ was slower than the period of the bilateral rhythmicity $(1.9 \mathrm{sec})$. The burst amplitude, on the other hand, was relatively similar in the two experimental situations.

Bilateral and unilateral rhythmic activity was compared in 18 preparations. Unilateral rhythmicity was significantly slower than bilateral rhythmicity (period mean $\pm \mathrm{SD}=3.77 \pm 1.35 \mathrm{sec}$ and $2.18 \pm 0.56 \mathrm{sec}$, respectively; $p<0.0001$, paired $t$ test; Fig. $2 C$ ). The slower unilateral rhythmic activity compared with the bilat- 
eral rhythm may suggest that the two halves of the network generating locomotor-related commands must interact to obtain a high-frequency output, as suggested previously (Kjaerulff and Kiehn, 1996).

In contrast to the change in period, neither the peak $\left(V R_{\max }\right)$ nor the trough $\left(V R_{\min }\right)$ amplitudes of the rectified and smoothed ventral root recordings differed significantly when comparing bilateral and unilateral rhythm (Fig. 2D).

\section{The crossed synaptic input to motoneurons during contralateral rhythmic ventral root activity}

All intracellular recordings included in this study were from rostral lumbar motoneurons defined by the criteria given in Materials and Methods. Stable recordings were obtained from 59 motoneurons. Most motoneurons projected through the L2 ventral root $(n=54)$, whereas two projected through the L1 and three through the L3 ventral root. The resting membrane potential was $-66 \pm 8 \mathrm{mV}$ (mean $\pm \mathrm{SD} ; n=45)$.

The basic observation of the present study is shown in Figure $1 B$ (also see Figs. $3 A, B ; 4 B ; 5 B-D, F ; 6 A, B$ ). We recorded intracellularly from an L2 motoneuron on one side of the cord. This side was kept in normal solution and showed no activity in the L2 ventral root. In contrast, on the contralateral side, rhythmic bursting was maintained in the L2 ventral root by superfusing with 5-HT and NMDA. During contralateral ventral root rhythmicity, a rhythmic potential was observed in the motoneuron, which was depolarizing with respect to the stable resting membrane potential observed before the onset of rhythmicity. The rhythmic potential was time-locked with a $1: 1$ relationship to the bursts in the contralateral ventral roots and will be termed the contralateral rhythm-related potential (CRRP) in the following.

Of 59 motoneurons recorded from during contralateral agonist-induced rhythmic activity, a CRRP was observed in 45 (76\%). The typical CRRP was in phase with the contralateral root; that is, the rhythmic depolarization of the membrane potential occurred concomitantly with the contralateral ventral root burst (Fig. 1B,C). Such an in-phase CRRP (iCRRP) was observed in 37 cases. In seven motoneurons, an out-of-phase CRRP (oCRRP) was observed; that is, the depolarization of the CRRP occurred concomitantly with the interburst interval in the contralateral ventral root. Finally, in one cell a clear double CRRP was seen: two distinct depolarizations per cycle, one in phase, and one out of phase with the contralateral burst.

First, we will concentrate on the iCRRP, the most common type of crossed rhythmic depolarization, which occurred in phase with the contralateral ventral root burst. The oCRRP will be treated briefly in a later section. Figure $3 A$ shows an iCRRP at the resting membrane potential (i.e., without current injection). To investigate how the iCRRP affected motoneuronal firing, the motoneurons were depolarized beyond the threshold for action potential generation by injecting direct current through the recording electrode. We found that firing was inhibited in phase with the contralateral bursts (Fig. $3 B$ ); that is, the motoneuron was inhibited in the same phase as that in which the iCRRP appeared as a rhythmic depolarization at the resting membrane potential. Thus, the iCRRP represented a barrage of IPSPs that were depolarizing at the resting membrane potential. IPSPs that are depolarizing at the resting membrane potential have been described previously in embryonic and early postnatal rat motoneurons (Jahr and Yoshioka, 1986; Wu et al., 1992) (also see Discussion). Our electrodes were highly rectifying, so that it was difficult to pass depolarizing current. Therefore, it was most often impossible to depolarize the cells sufficiently to obtain the firing intensity necessary to determine the effect of the iCRRP on spike activity. However, in addition to the motoneuron shown in Figure 3 , we succeeded in two more motoneurons to demonstrate that the iCRRP represented a rhythmic inhibitory input in phase with the contralateral burst. These recordings were made with potassium acetate electrodes or low-chloride electrodes (compare recordings with high-chloride electrodes below).

When recorded with electrodes containing little or no chloride, the iCRRP often showed a small amplitude (Fig. $3 A$ ) and sometimes even appeared to be absent (Fig. $4 A$ ). However, when the motoneurons were hyperpolarized with current injection, the iCRRP amplitude immediately increased, and consequently the presence of an iCRRP became evident (Fig. 3C). Attempts to reverse the polarity of the iCRRP by depolarizing the motoneurons were hampered by the large resistance of the electrodes to depolarizing current (see above).

\section{Ionic mechanism underlying the CRRP}

It is well established that rhythmic inhibition of spinal motoneurons during locomotor activity is mediated by chloride-dependent IPSPs (Roberts et al., 1983; Russell and Wallén, 1983, Orsal et al., 1986, Cazalets et al., 1996). If the iCRRP is also composed of chloride-dependent IPSPs, shifting the chloride reversal potential $\left(E_{\mathrm{C} 1}\right)$ in the depolarizing direction should increase the iCRRP amplitude measured at the resting membrane potential. To obtain this positive shift in $E_{\mathrm{Cl}}$, chloride ions were included in the electrode solution, and negative current was injected to increase the intracellular chloride concentration (Coombs et al., 1955). As illustrated in Figure 4, comparing $A$ with $B$, the iCRRP was more prominent in recordings with chloride-containing electrodes than in recordings with potassium acetate electrodes. Furthermore, on hyperpolarization, in addition to the prompt iCRRP amplitude increase seen also with potassium acetate electrodes, a slowly developing amplitude increase was observed in recordings with chloride-containing electrodes (data not shown). This was likely a result of a shift in $E_{\mathrm{C} 1}$, which was accelerated by actively pumping chloride ions into the cell when passing hyperpolarizing current. The particularly high amplitude of the iCRRP sometimes observed with chloride-containing electrodes made it easy to distinguish that the iCRRP was composed of a barrage of individual brief depolarizing potentials. This is seen, e.g., in Figure $5 B-D$. These panels also show that the amplification of the iCRRP could be sufficient to trigger the firing of action potentials even when the cells were hyperpolarized with direct current.

To evaluate quantitatively the changes in the iCRRP associated with the use of chloride-containing electrodes, we sorted the motoneurons by the electrode solution involved and used a statistical criterion in individual cells to judge whether a significant CRRP was present at the resting membrane potential (see Materials and Methods). As explained in Figure $1 C$, we determined the difference, $\Delta V_{\mathrm{m}}$ (root), between the membrane potential sampled at the time $\left(t_{\mathrm{VR \operatorname {max }}}\right)$ of the peak amplitude $\left(V R_{\max }\right)$ of the contralateral ventral root burst and at the time $\left(t_{\mathrm{VRmin}}\right)$ of the ensuing trough $\left(V R_{\min }\right)$. Figure $4 C$ shows that a large majority of $\Delta V_{\mathrm{m}}$ (root) values were positive, representing potential iCRRPs, whereas only a minority were negative, representing potential oCRRPs. The absolute value of $\Delta V_{\mathrm{m}}$ (root) was generally larger when obtained from recordings with chloride-containing electrodes than when obtained from recordings with potassium acetate electrodes. Also, the proportion of cells with a significant CRRP was higher when chloride ions were included in the elec- 
A

VR-iL2

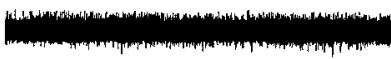

$5-H T+N M D A$

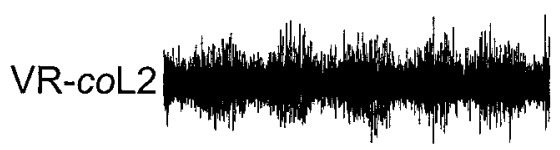

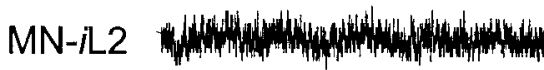

$0.00 \mathrm{nA}$

B

VR-IL2

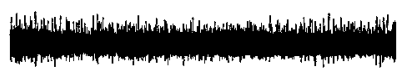

$5-\mathrm{HT}+\mathrm{NMDA}$

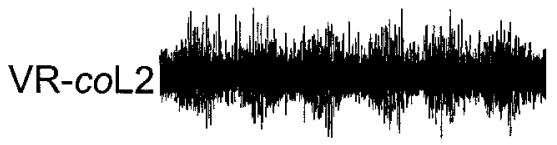

MN-iL2

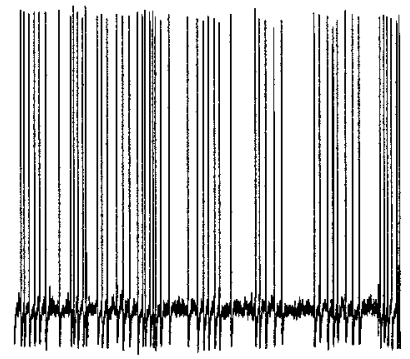

+0.40 nA
VR-iL2

$5-H T+N M D A$

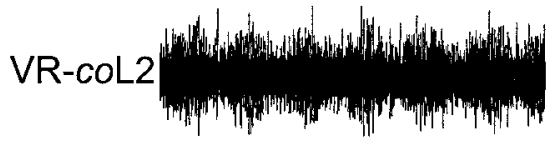

MN-iL2

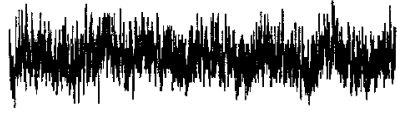

$-0.35 \mathrm{nA}$

strychnine

VR-iL2

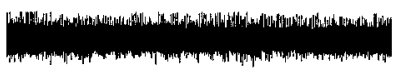

5-HT + NMDA

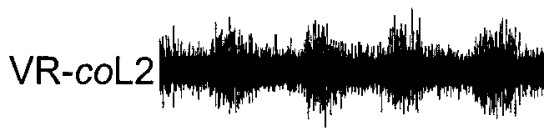

strychnine

MN-il22

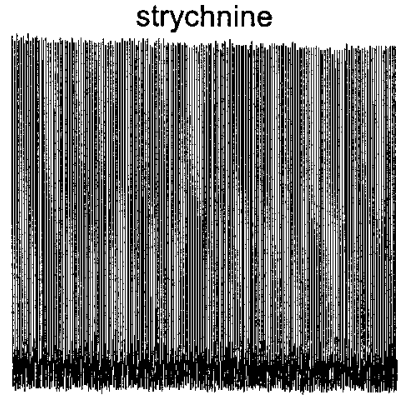

$+0.40 \mathrm{nA}$

A,C: $10 \mathrm{mV}$

B,D: $20 \mathrm{mV}$

$5 \mathrm{~s}$

Figure 3. Voltage dependency and strychnine sensitivity of the iCRRP. Unilateral ventral root bursting (middle trace in $A-D)$ was induced by adding $15.0 \mu \mathrm{M}$ 5-HT and 7.5 $\mu \mathrm{M}$ NMDA selectively to the compartment opposite from the intracellular recording compartment. A low-amplitude iCRRP was observed at the resting membrane potential in the motoneuron ( $A$, bottom trace). The iCRRP represented a barrage of IPSPs that were depolarizing at the resting membrane potential $(A)$ but that inhibited spike activity induced by depolarizing direct current. This inhibition occurred in phase with the contralateral burst $(B)$. The iCRRP amplitude increased after injecting hyperpolarizing direct current $(C$; current indicated at bottom trace). The rhythmically modulated firing seen in control $(B)$ became tonic when strychnine $(1.0 \mu \mathrm{M})$ was added to the intracellular compartment, indicating that strychnine blocked the iCRRP $(D)$. The microelectrode contained $0.5 \mathrm{~m}$ potassium acetate and $0.5 \mathrm{M} \mathrm{KCl}$. 


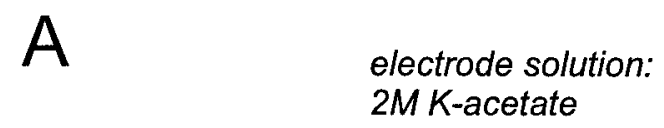

VR-IL2

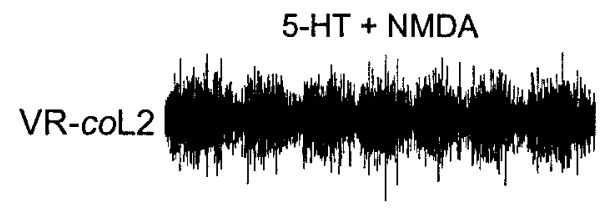

MN-R2

electrode solution: $1 \mathrm{M} \mathrm{KCl}+1 \mathrm{MK}$-acetate

VR-iL2

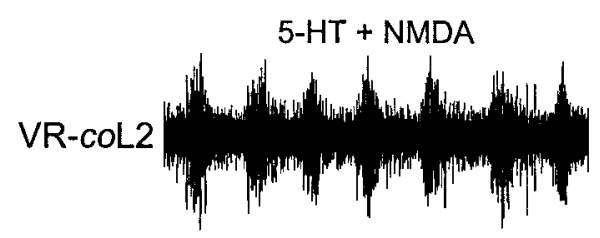

$\mathrm{MN}-\mathrm{l}$ 2

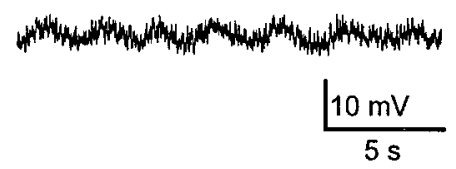

C no $\mathrm{Cl}^{-}$

$\mathrm{Cl}^{-}$

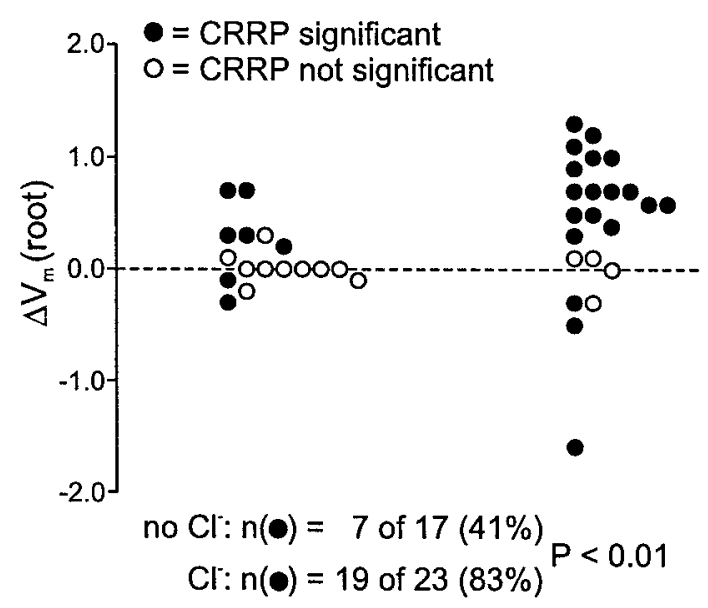

Figure 4. Chloride dependency of the iCRRP. A, Unilateral rhythmic activity induced by adding $6.0 \mu \mathrm{M} 5$-HT and $6.0 \mu \mathrm{M}$ NMDA selectively to the compartment opposite from the intracellular recording compartment. A potassium acetate electrode was used for intracellular recording (bottom trace), and no systematic membrane potential fluctuations were ob- trode than when they were not $(19$ of $23=0.83$ and 7 of $17=0.41$, respectively; $p<0.01, \chi^{2}$ test). Because the sample was dominated by iCRRPs, the general chloride-dependent amplification of the rhythmic depolarization suggests that the IPSPs underlying the iCRRP were chloride-dependent. With regard to the oCRRP, one high-amplitude oCRRP was observed in recordings with chloride-containing electrodes, but because there was otherwise no change in the amplitude of the oCRRPs and because of the small number of oCRRPs, no firm conclusion can be reached about the chloride dependence of the oCRRP from the set of experiments treated in this section.

With potassium acetate electrodes, and occasionally with lowchloride electrodes, the iCRRP was found to be inhibitory, reducing the frequency of firing in phase with the contralateral burst (see above). This is supposedly the "normal" action of the iCRRP (see Discussion). In recordings with $\mathrm{KCl}$ electrodes (lowand high-chloride recordings pooled), the effect on the firing pattern was generally different. Thus, of 16 motoneurons recorded with $\mathrm{KCl}$ electrodes and all showing an iCRRP, 15 motoneurons fired dominantly in phase with the contralateral burst when depolarized (Fig. 5A), instead of showing inhibition in this phase, as observed with potassium acetate electrodes. We suggest that this chloride-dependent switch from inhibited to predominant firing in phase with the contralateral burst occurred because the normally weakly depolarizing chloride-dependent IPSPs underlying the iCRRP became so strongly depolarizing after injection of chloride that they underwent a functional switch to become excitatory and to promote intense firing in phase with the contralateral burst.

\section{The effect of inhibitory amino acid receptor antagonists on the iCRRP}

The ionotrophic glycine or GABA $_{\mathrm{A}}$ receptors (Nicoll et al., 1990) appear likely to be involved in the generation of the iCRRP, because our data suggest that the iCRRP is a chloride-dependent rhythmic inhibition. Antagonists of these receptors were therefore added selectively to the intracellular recording compartment, whereas 5-HT and NMDA were added to the contralateral compartment to induce rhythmic activity, as before.

In Figure $3 D$, strychnine, a glycine receptor antagonist, clearly blocked the rhythmic inhibition observed in normal medium (Fig. $3 B$ ). Another motoneuron (Fig. 5) was hyperpolarized with direct current injection to amplify the iCRRP and thus to observe better the effect of the antagonists. In this motoneuron, the iCRRP was largely unaffected by bicuculline, a $\mathrm{GABA}_{\mathrm{A}}$ receptor antagonist (Fig. 5, compare $C, B$ ), whereas strychnine almost abolished the iCRRP (Fig. 5, compare $E, D$ ). The iCRRP partially recovered after washout of strychnine (Fig. $5 F$ ).

The effect of strychnine on the iCRRP was tested in six motoneurons. In four of these, the iCRRP was blocked. In the last

$\leftarrow$

served in the motoneuron despite well developed contralateral bursting (middle trace). $B$, Recording with a chloride-containing microelectrode from another motoneuron in the same preparation. Note the prominent iCRRP. Contralateral rhythmicity was induced with the same 5-HT and NMDA concentrations as in $A$. $C$, Diagram of CRRP amplitudes from recordings with potassium acetate electrodes $\left(\mathrm{no} \mathrm{Cl}^{-}\right)$and with chloridecontaining electrodes $\left(\mathrm{Cl}^{-}\right)$. CRRP amplitudes were measured as $\Delta V_{\mathrm{m}^{-}}$ (root) at the resting membrane potential. Each value is from a different motoneuron. Filled circles indicate values significantly different from zero. Positive values represent iCRRPs, whereas negative values represent oCRRPs. Values indicated with open circles did not differ significantly from zero. 


\section{A}

VR-iL3

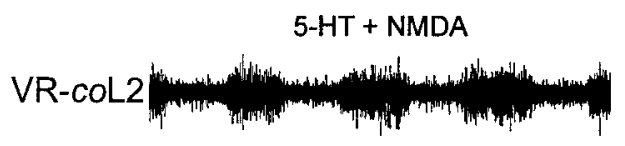

MN-ill3

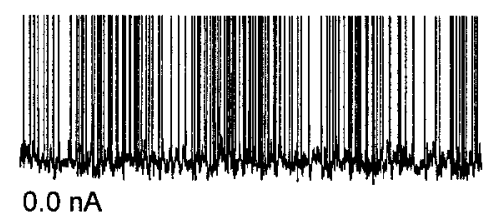

D

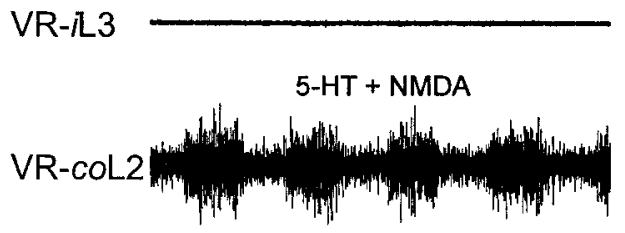

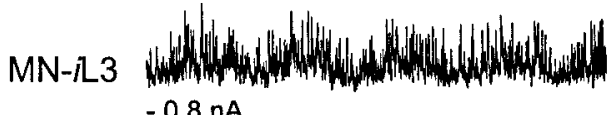

B
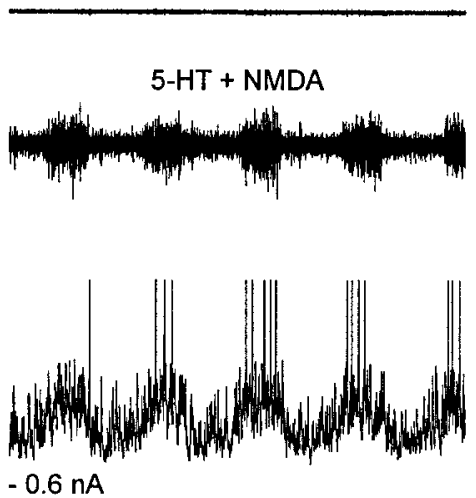

E

strychnine

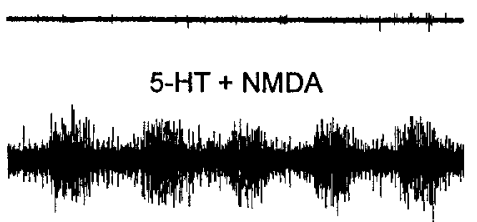

strychnine

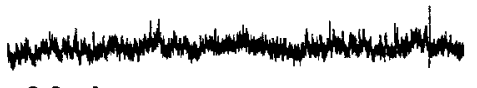

C

bicuculline
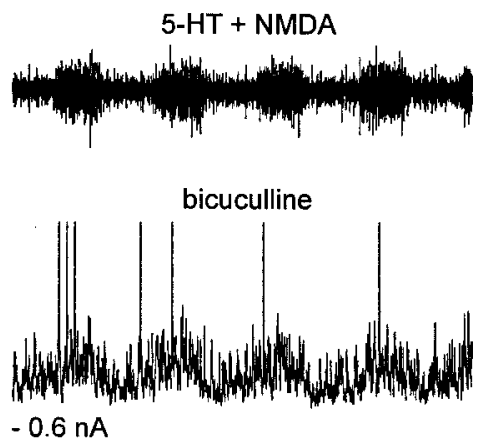

F

wash-out strychnine

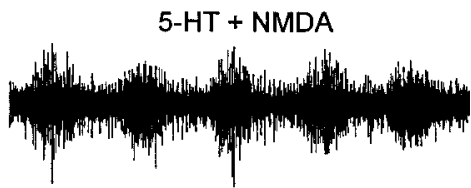

wash-out strychnine

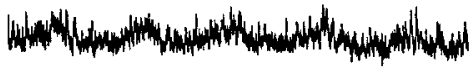

$-0.8 \mathrm{nA}$

Figure 5. Effects of bicuculline and strychnine on the iCRRP. Unilateral rhythmic activity induced by adding 7.5 $\mu \mathrm{M} 5$-HT and 7.5 $\mu \mathrm{M}$ NMDA to the compartment opposite from the intracellular recording compartment. $A$, Before current injection, the motoneuron (bottom trace) fired rhythmically, with the maximal firing frequency during the contralateral burst. $B$, A high-amplitude iCRRP was revealed when hyperpolarizing the motoneuron (current indicated at bottom trace). $C$, Bicuculline $(10 \mu \mathrm{M})$, added to the intracellular recording compartment, was unable to block the iCRRP. $D$, After washing out bicuculline, 5-HT, and NMDA (not shown), contralateral ventral root rhythmicity and the iCRRP were reinduced by adding 5-HT and NMDA again. The iCRRP was blocked by strychnine $(10 \mu \mathrm{M})$ added to the intracellular recording compartment $(E)$; this block was partially reversible $(F)$. The action potentials are truncated in $A-F$. The microelectrode contained $1 \mathrm{M} \mathrm{KCl}$.

two motoneurons, however, strychnine appeared unable to block the iCRRP. Bicuculline was tested on four motoneurons. In three cells, the iCRRP was not affected, whereas in the last motoneuron bicuculline diminished, without blocking, the iCRRP. Based on these experiments we conclude that the iCRRP was mediated by glycine receptors. However, GABA ${ }_{\mathrm{A}}$ receptors might also be involved, because strychnine was not $100 \%$ effective in blocking the iCRRP, and because bicuculline seemed to have an effect in one case.

In two of the experiments (one with strychnine and one with bicuculline) in which the inhibitory amino acid antagonists had no effect on the iCRRP, irregular bursting developed in the ventral root on the side of the spinal cord exposed to the antagonist (data not shown). A similar phenomenon has been described previously in conjunction with bilateral application of antagonists of inhibitory transmission (Cowley and Schmidt, 1995, Bracci et al., 1996). The activation of rhythm-generating networks after adding inhibitory amino acid antagonists on the side of the intracellular recordings may be of relevance when evaluating the effect of these blockers (see Discussion).

\section{The organization of the pathways mediating the iCRRP, analyzed with glutamate receptor antagonists}

An important suggestion from the data presented thus far is that, in the neonatal rat, the half of the $\mathrm{CPG}$ located in one hemicord 
phasically inhibits contralateral motoneurons. This crossed inhibition, the iCRRP, may be mediated by a direct monosynaptic projection, analogous to the reported organization in simpler vertebrate systems (see Discussion). Another possibility, however, is that the rhythmic inhibition is mediated by a crossed excitatory pathway that activates inhibitory relay interneurons located on the same side as the motoneurons. If this latter hypothesis holds true, it should be possible to block the excitation of the putative relay neurons, and thereby the iCRRP, with excitatory neurotransmitter antagonists added to the intracellular recording compartment. Glutamate receptors are likely to mediate the crossed excitation of the putative inhibitory relay interneurons. These receptors are commonly involved in neural excitation, and their stimulation has consistently been found to play a key role in the generation of spinal rhythmic activity (see Douglas et al., 1993, and references therein). Therefore, we tested whether glutamate receptor antagonists were able to block the iCRRP, using APV and CNQX, which are antagonists of the NMDA and the nonNMDA glutamate receptor subtypes, respectively. Such an experiment is illustrated in Figure 6. In control (Fig. 6A-C), in which the intracellular recording compartment was kept in normal medium during contralateral rhythmic activity, a weak iCRRP was observed at the resting membrane potential (Fig. 6 $A$ ) and, more clearly, after hyperpolarization (Fig. 6B). The iCRRP rhythmically inhibited firing of the motoneuron elicited by depolarizing direct current injection; this inhibition occurred in phase with the contralateral bursts, as discussed already (Fig. 6C). When APV and CNQX in combination were added to the intracellular recording compartment, any signs of rhythmic inhibition from the contralateral side disappeared (Fig. $6 D-F$ ). To increase the confidence that this effect was in fact attributable to a pharmacological action of APV and CNQX, we recorded the compound EPSP evoked by stimulating the L2 dorsal root in the intracellular recording compartment before (Fig. 6A) and after (Fig. 6D) adding APV and CNQX to this compartment. Before APV and CNQX, dorsal root stimulation (Fig. $6 A$, arrowhead), in addition to evoking the compound EPSP (Fig. $6 A$, arrow), also reduced the duration of the contralateral burst during which it was applied. This effect was associated with resetting of the contralateral rhythm (cf. Fig. 6, legend) (also see Kiehn et al., 1992). APV and CNQX, when added to the intracellular recording compartment, blocked the compound EPSP evoked by dorsal root stimulation, as reported previously (Jahr and Yoshioka, 1986; Jiang et al., 1990; Pinco and Lev-Tov, 1993). In addition, the effect on the burst duration and the resetting effect were abolished (Fig. 6D). These results suggest that the iCRRP originating from the contralateral rhythm-generating network is mediated by crossed glutamatergic pathways that rhythmically excite relay neurons located on the same side as the recorded motoneurons, and that these relay neurons in turn inhibit the ipsilateral motoneurons.

Pooling the results from similar experiments, we found that the iCRRP amplitude was reduced to $21 \pm 25 \%$ of control after adding APV and CNQX [mean $\pm \mathrm{SD} ; n=6$ motoneurons; iCRRP amplitude determined as $\Delta V_{\mathrm{m}}$ (root)]. Expressed with the median, the $\Delta V_{\mathrm{m}}$ (root) was reduced to $9 \%$ of control. Although the iCRRP was largely blocked in four motoneurons, it was much less affected in the last two of the six motoneurons (iCRRP reduced to 42 and $69 \%$ of control). We suggest that in these motoneurons, in which APV and CNQX did not efficiently block the iCRRP, the crossed rhythmic inhibition was mediated at least partly by a direct pathway, rather than a pathway including inhibitory relay neurons.
It is a common phenomenon in our preparation that bursting becomes less vigorous after prolonged chemically induced rhythmic activity (Sqalli-Houssaini et al., 1993; Kjaerulff et al., 1994). In addition to this "rundown," some of the antagonists could, in principle, eventually have crossed the midline by diffusion and inhibited the contralateral rhythm-generating network in some preparations. In view of these considerations, it could be argued that the reduction in the iCRRP amplitude seen with EAA antagonists was an indirect consequence of less intense activity in the contralateral rhythm-generating network, rather than a direct block of a crossed excitatory input to ipsilateral inhibitory relay neurons mediating the iCRRP. To look further into this issue, we compared the reduction in the iCRRP amplitude, observed after adding APV and CNQX ipsilaterally, with the time-dependent changes in the contralateral burst amplitude (Fig. 7A) and frequency (Fig. $7 B$ ) and also with the reduction in the compound EPSP evoked by dorsal root stimulation (Fig. 7C). Figure $7 A$ shows that at the time at which the iCRRP was blocked or strongly reduced, the peak amplitude $\left(V R_{\max }\right)$ of the contralateral burst was generally unaffected. The frequency of the contralateral rhythm was slightly more affected than the amplitude (Fig. 7B). However, in two experiments (Fig. 7B, 3,4) the frequency was virtually unchanged. In contrast to these small changes in contralateral rhythmicity, the dorsal root response was blocked or strongly reduced (Fig. $7 C$ ). In view of these results, we conclude that the effect of APV and CNQX on the iCRRP was not related to a reduction in the intensity of the contralateral ventral root rhythmicity.

\section{The pharmacology and possible nature of the oCRRP}

The effect of specific antagonists on the CRRP occurring out of phase with the bursts in the contralateral root (the oCRRP) was tested in a few experiments (data not shown). In one motoneuron, CNQX and APV blocked the oCRRP. In a second motoneuron, in which strychnine was used, the oCRRP was unaffected by the antagonist. Finally, one motoneuron showed both an oCRRP and an iCRRP in each cycle. An occasional spike was observed on top of the oCRRP, but none was observed in relation to the iCRRP. CNQX and APV added to this motoneuron blocked the component out of phase with the contralateral burst but had no effect on the in-phase component.

Although these data are too scant to allow a firm conclusion regarding the nature of the oCRRP, the results indicate that the oCRRP most likely reflects an excitatory input mediated by glutamate receptors.

\section{Motoneuronal identity, firing pattern, and synaptic drive during bilateral rhythmic activity}

It remains unknown which muscles the rostral lumbar motoneurons included in this study innervate. However, our sample is probably biased toward iliopsoas and quadriceps motoneurons. First, in combined spinal cord-hindlimb preparations, the iliopsoas and quadriceps muscles are all active in the same phase as the bursts in the ipsilateral L2 ventral roots when 5-HT, with or without NMDA, is used to induce rhythmic activity (Kiehn and Kjaerulff, 1996; Iiizuka et al., 1997). In accordance with this phase relationship, almost all of the motoneurons in the present study received an excitatory drive in phase with the bursts in the ipsilateral L1-L3 ventral roots during bilateral rhythmic activity (see next paragraph). Second, anatomical studies (NicolopoulosStournaras and Iles, 1983) have shown that the iliopsoas and quadriceps motor columns are located superficially in the L1-L3 
A

VR-iL2

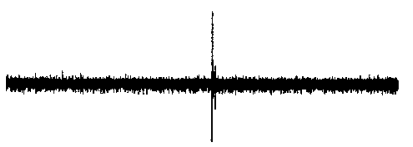

$5-H T+N M D A$

VR-col2

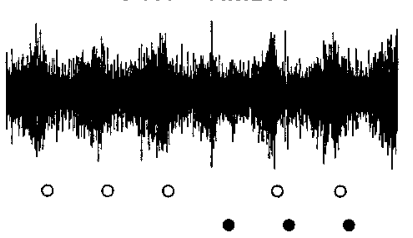

MN-iL2

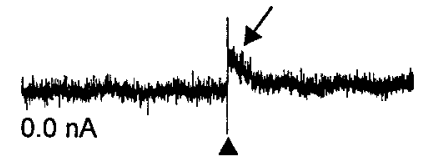

D

$A P V+C N Q X$

VR-iL2

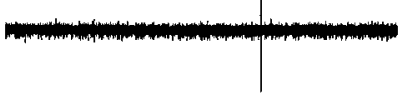

VR-coL2

$\mathrm{APV}+\mathrm{CNQX}$

MN-iL2

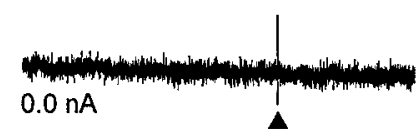

B
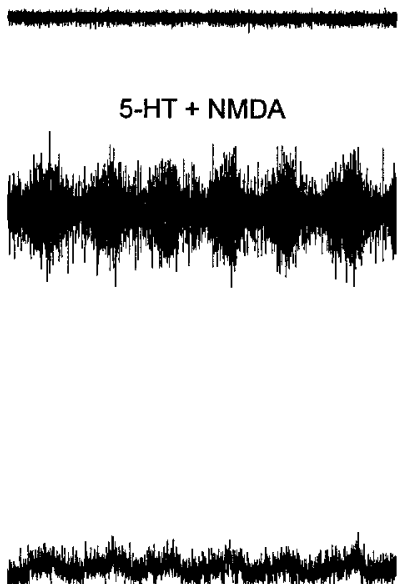

$-0.6 \mathrm{nA}$

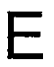

$A P V+C N Q X$

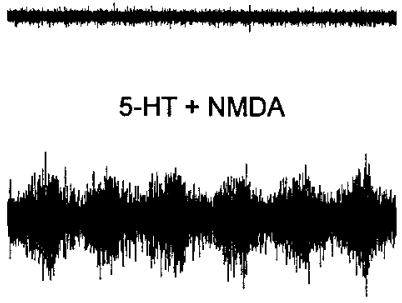

$A P V+C N Q X$

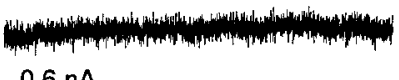

C
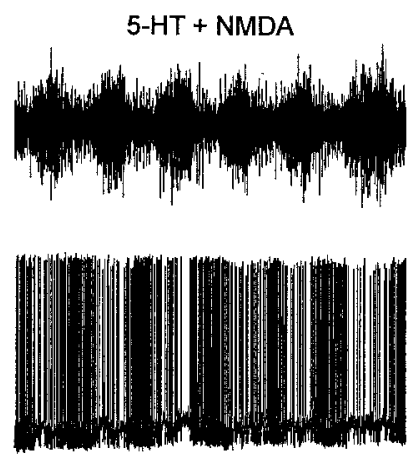

$+1.1 \mathrm{nA}$
F

$\mathrm{APV}+\mathrm{CNQX}$

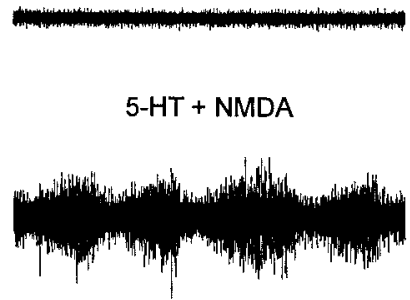

$A P V+C N Q X$

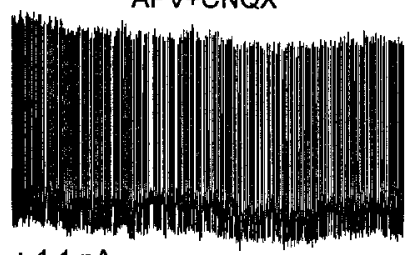

$+1.1 \mathrm{nA}$

$\frac{\mid \begin{array}{l}\text { A, B, D, E: } 10 \mathrm{mV} \\ \text { C, F: } 25 \mathrm{mV}\end{array}}{5 \mathrm{~s}}$

Figure 6. Evidence suggesting that the crossed synaptic transmission of the iCRRP is polysynaptic. $A$, Unilateral rhythmic ventral root activity (middle trace) induced by adding $6.0 \mu \mathrm{M} 5$-HT and $6.0 \mu \mathrm{M}$ NMDA to the compartment opposite from the intracellular recording compartment. $A$, In the motoneuron recorded on the agonist-free side, a small-amplitude iCRRP was barely visible before injecting current but became more obvious after hyperpolarizing the cell $(B)$. Firing induced with depolarizing current (indicated at bottom trace) was inhibited in phase with the contralateral bursts $(C)$. In $A$, stimulation (arrowhead) of the L2 dorsal root on the same side as the motoneuron elicited a compound EPSP (arrow). Dorsal root stimulation also truncated the ongoing contralateral ventral root burst and reset the rhythm by advancing the offsets of the poststimulus bursts (open circles) relative to the offsets forecasted from the prestimulation offsets ( filled circles). $D-F$, Effects of EAA antagonists. Adding APV (30 $\mu \mathrm{M})$ and CNQX ( $2 \mu \mathrm{M})$ to the intracellular recording compartment blocked the iCRRP despite maintained contralateral bursting. Thus, both the rhythmic depolarization at the resting $(D)$ and hyperpolarized $(E)$ membrane potentials and the rhythmic inhibition of motoneuronal firing were abolished. In APV and CNQX, dorsal root stimulation no longer elicited an EPSP and was now without effect on contralateral rhythmicity $(D)$. In $F$, a prominent DC shift caused by a progressive block of the electrode current has been eliminated by high-pass filtering off-line at $0.1 \mathrm{~Hz}$. The microelectrode contained $2 \mathrm{M}$ potassium acetate. 


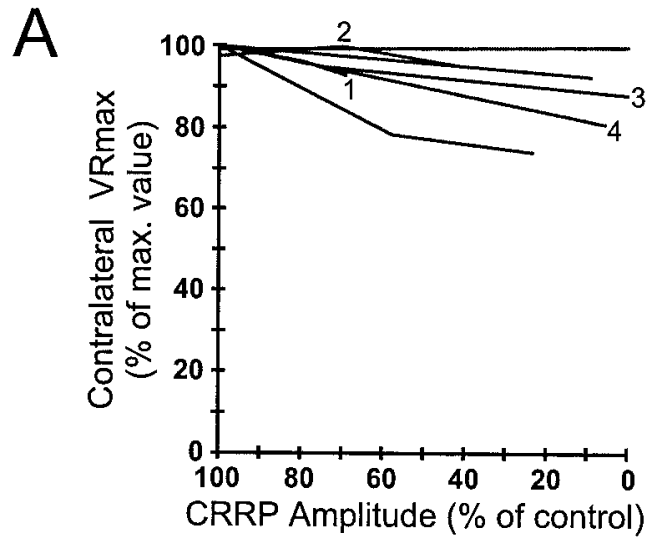

$\mathrm{B}$

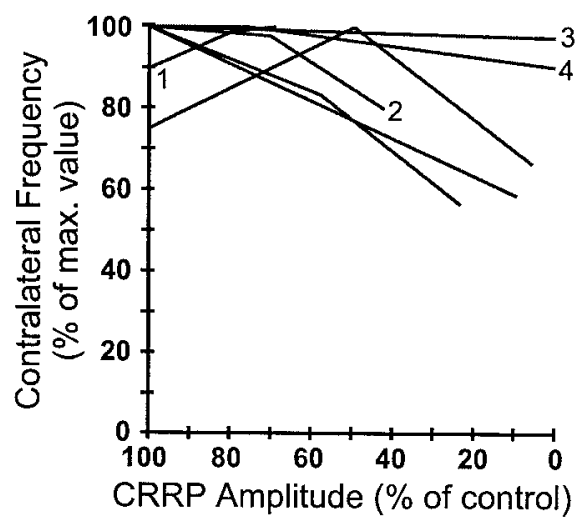

C

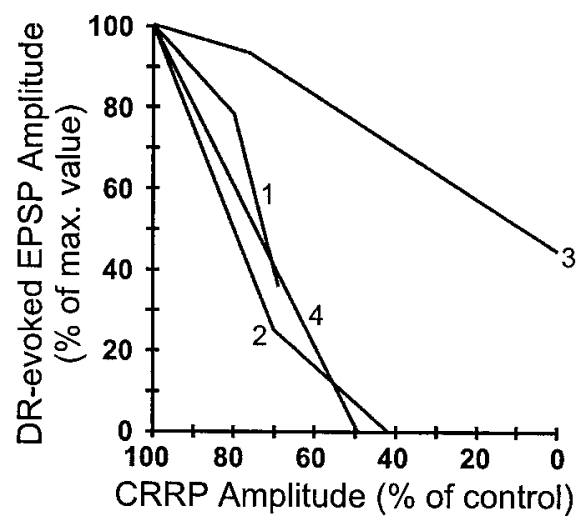

Figure 7. The effect of the excitatory amino acid antagonists APV and CNQX on the maximal burst amplitude $(A)$ and burst frequency $(B)$ of the contralateral rhythmic ventral root activity. The effect of APV and CNQX on the dorsal root-evoked compound EPSP is also shown $(C)$. All effects $(A-C)$ have been related to the effect of the blockers on the iCRRP. In all panels, the $x$-axis indicates the iCRRP amplitude as the experiments progressed. Note the reversed scale on the $x$-axis. Values on the $x$-axis were normalized by dividing them with the control value measured shortly before the application of EAA antagonists. Likewise, values on the $y$-axis were normalized to the maximal values (generally those measured before antagonist application). Each curve represents a different motoneuron. Curves labeled with an identical number in $A-C$ are from the same experiment. The iCRRP amplitude was measured as $\Delta V_{\mathrm{m}}$ (root) (see Materials and Methods).

region. Motoneurons in these columns were therefore the most likely to be included in our sample, because we usually recorded relatively superficially (distance between surface and electrode tip, $\sim 100-300 \mu \mathrm{m})$.
In most of the motoneurons, in addition to recording during contralateral rhythmicity, we also recorded the input during bilateral rhythmicity induced by exposing both sides of the spinal cord to 5-HT and NMDA. We did this to determine directly the phase relationship between the motoneurons and the bursts in the corresponding ipsilateral ventral roots; this information is necessary in placing the CRRPs in a functional context (see Discussion). The recorded motoneurons generally projected through that ipsilateral ventral root from which we recorded concurrently (generally VR-iL2, but also VR-iL1, or VR-iL3). A priori, most of the motoneurons would therefore be expected to be mainly active in phase with the dominant flexor-related burst in this root. This notion was confirmed, because during bilateral rhythmicity, 34 of 35 motoneurons fired action potentials either exclusively $(n=28)$ or dominantly $(n=6)$ in phase with the bursts in the ipsilateral ventral root (Fig. $8 A, B$ ). Only one motoneuron fired out of phase with the ipsilateral ventral root burst; i.e., it was extensor-related.

The appearance of the synaptic input during bilateral rhythmic activity depended on the microelectrode solution. Motoneurons impaled with potassium acetate electrodes (or low-chloride electrodes) showed one depolarization per cycle, which occurred in phase with the burst in the ipsilateral ventral root (Fig. $8 A$, filled arrow). With high-chloride electrodes, in addition to this excitatory drive potential (Fig. $8 B$, filled arrows), a second prominent depolarization occurred out of phase with the ipsilateral ventral root burst (Fig. 8B, open arrow). Presumably, this second depolarization resulted from the summation of depolarizing $\mathrm{Cl}^{-}$dependent IPSPs, which were amplified by $\mathrm{Cl}^{-}$loading of the cell. This notion is supported by several studies of the rhythmic inhibition of motoneurons during spinal rhythmicity (Russell and Wallén, 1983; Orsal et al., 1986, Robertson and Stein, 1988, Cazalets et al., 1996) and by the absence of the second depolarization in recordings with potassium acetate electrodes (Fig. 8A).

In conclusion, during bilateral rhythmic activity, the motoneurons in this study were excited and fired in phase with the single dominant flexor-related burst in the corresponding ipsilateral ventral roots, and they received an inhibition during the ipsilateral interburst interval. Because this firing pattern was general, it was characteristic of both the motoneurons that received an iCRRP during contralateral rhythmicity and those that received an oCRRP.

\section{DISCUSSION}

We have shown that it is possible, by selectively exposing one-half of the spinal cord to rhythm-inducing agonists, to obtain rhythmic activity in the ventral roots on the agonist-exposed side but to totally avoid ventral root rhythmicity on the opposite, agonistfree side. Furthermore, we have shown that L1-L3 motoneurons typically receive a rhythmic inhibitory input in phase with the contralateral ventral root bursts during selective contralateral ventral root rhythmicity. We have termed this input the in-phase contralateral rhythm-related potential (iCRRP). In a minority of motoneurons, we observed a rhythmic input, which instead occurred out of phase with the bursts in contralateral ventral root and which we therefore term the oCRRP. We suggest that both the iCRRP and the oCRRP are mediated by pathways that originate in the contralateral locomotor network and cross to the motoneurons on the agonist-free side.

For convenience, we will use the term "hemi-CPG" to denote the part of the locomotor-controlling network that is located in one-half (hemicord) of the spinal cord. Furthermore, we will here assume the simplistic view that each hemi-CPG consists of two 
A

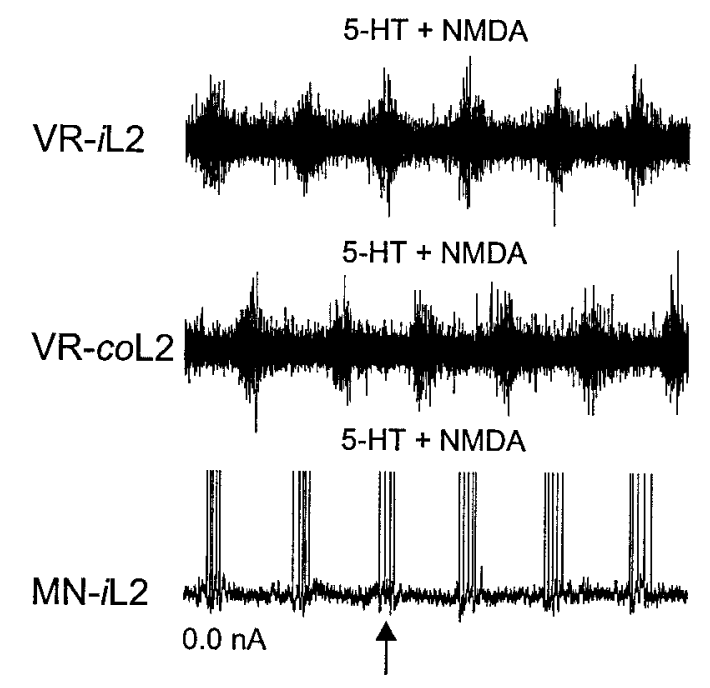

B

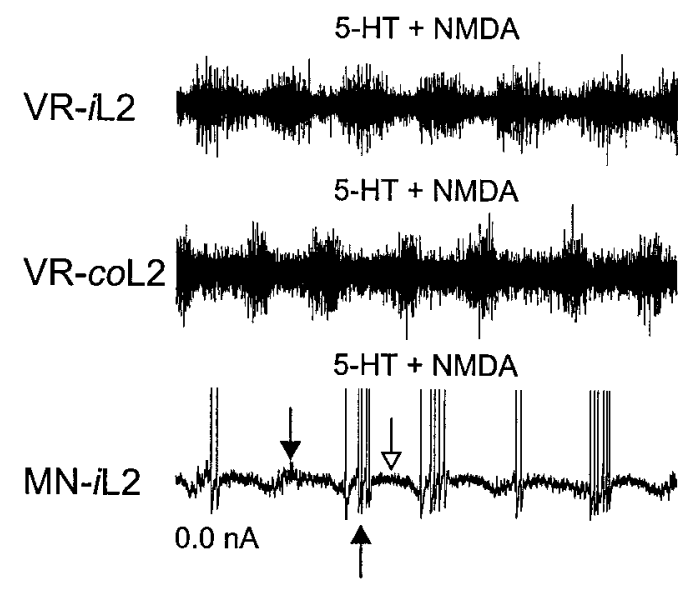

$25 \mathrm{mV}$

$5 s$

Figure 8. Synaptic input to motoneurons during bilateral ventral root rhythmicity induced by superfusing both sides of the spinal cord with 5-HT and NMDA. $A$, Recording with a potassium acetate electrode. In the motoneuron (bottom trace) only an excitatory drive ( filled arrow) that induced firing in phase with the ipsilateral ventral root burst (top trace) was visible. $B$, Recording with a chloride-containing electrode from a different motoneuron (same cell as in Fig. 4). As in $A$, an excitatory drive in phase with the burst in the ipsilateral ventral root was observed ( filled arrows; two depolarizations in two different cycles are indicated, the first appearing without superimposed spikes). In addition, a second depolarization, which peaked during the ipsilateral burst offset, was seen (open arrow). The microelectrode in $A$ contained 2 m potassium acetate. The electrode in $B$ contained $1 \mathrm{M}$ potassium acetate and $1 \mathrm{M} \mathrm{KCl}$. Spikes are truncated in both $A$ and $B$. Concentrations: $A, 6.0 \mu \mathrm{M}$ 5-HT and $6.0 \mu \mathrm{M}$ NMDA (both sides); $B, 7.5 \mu \mathrm{M}$ 5-HT and $7.5 \mu \mathrm{M}$ NMDA (ipsilaterally), $15.0 \mu \mathrm{M}$ 5-HT and 7.5 $\mu \mathrm{M}$ NMDA (contralaterally). independent burst generators (Grillner, 1981), which control antagonistic actions (generalized flexion vs generalized extension) and which are normally tightly coupled in a manner ensuring that they produce alternating bursts (Fig. 9).

\section{Methodological considerations}

Although we believe that only the hemi-CPG located in the contralateral hemicord exposed to rhythm-inducing agonists was activated during unilateral ventral root activity, we cannot completely rule out that agonists diff using across the preparation also activated the (nominally) agonist-free ipsilateral hemi-CPG. A part of the CRRP, be it the iCRRP or the oCRRP, could then have originated from the ipsilateral hemi-CPG, rather than exclusively from the contralateral hemi-CPG. However, we consider this possibility unlikely, based on the following arguments. (1) We deliberately used concentrations on the contralateral side that were near the threshold for unilateral ventral root rhythmicity. Therefore, the ipsilateral hemi-CPG was exposed to even lower concentrations, because the laws governing simple diffusion require that the concentration decreases in the direction of the net movement of the diffusing substance. (2), During the startup phase of bilateral rhythmicity, in which the ipsilateral hemi-CPG was recruited in addition to the contralateral hemi-CPG, we observed a strong depolarization in the motoneurons $(15.0 \pm 5.9$ $\mathrm{mV} ; n=23)$. If, as a result of crossed diffusion, the ipsilateral hemi-CPG was also activated during selective contralateral ventral root activity, one would expect a similar depolarization to occur in the ipsilateral motoneurons. This was not seen. In fact, the ipsilateral motoneurons did not depolarize significantly during the startup phase of contralateral ventral root rhythmicity (the depolarization amounted to $1.5 \pm 2.2 \mathrm{mV} ; n=44)$. (3), We were unsuccessful when attempting to use methylene blue as an indicator substance for the rhythm-inducing agonists 5-HT and NMDA (see Materials and Methods). However, in some experiments we added the excitatory amino acid antagonists APV and CNQX to the agonist-free compartment during contralateral rhythmicity. APV and CNQX generally did not affect the contralateral rhythm (Fig. $7 A, B$ ), as would be expected if they diffused extensively to the contralateral hemicord. This result also suggests that crossed diffusion was not a major problem in this study, although the diffusion of APV and CNQX may not exactly represent the diffusion of the rhythm-inducing agonists 5-HT and NMDA.

To conclude, we suggest that the CRRP observed in the motoneurons was primarily a crossed input originating from the active contralateral hemi-CPG, rather than from the ipsilateral hemi-CPG.

\section{The iCRRP}

Our results indicate that the synaptic input forming the iCRRP was a barrage of depolarizing IPSPs, because we found that the iCRRP inhibited spike activity induced by depolarizing current. The iCRRP amplitude was increased by shifting the $\mathrm{Cl}^{-}$reversal potential in the depolarizing direction, suggesting that the depolarizing IPSPs were $\mathrm{Cl}^{-}$-dependent. IPSPs that are depolarizing at the resting membrane potential have been described before in our preparation (Jahr and Yoshioka, 1986; Wu et al., 1992). Furthermore, glycine (and GABA) ejected onto spinal motoneurons elicits $\mathrm{Cl}^{-}$currents that are depolarizing at rest. These currents reduce motoneuron excitability, probably because they are associated with a large conductance increase, which shunts excitatory currents (Gao and Ziskind-Conhaim, 1995). It is likely 
A

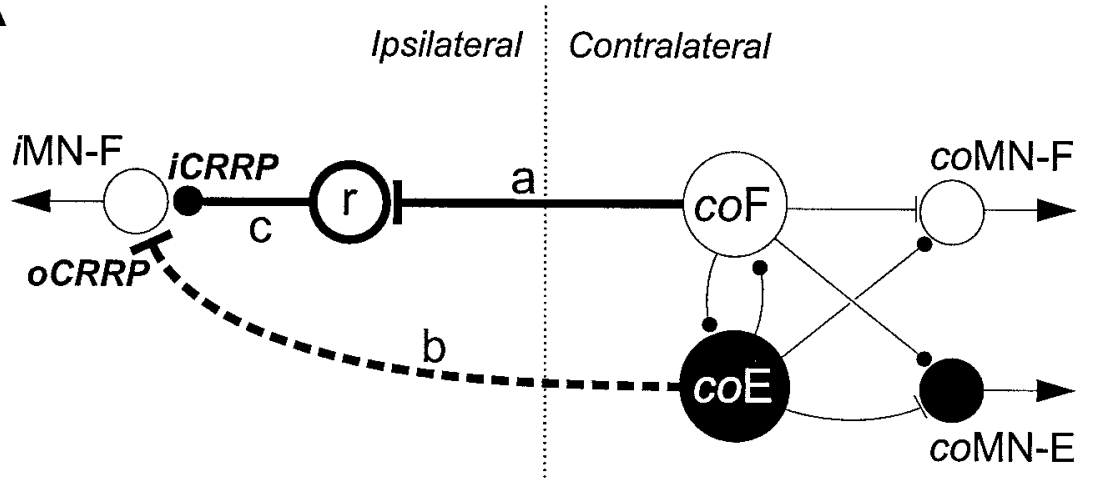

B

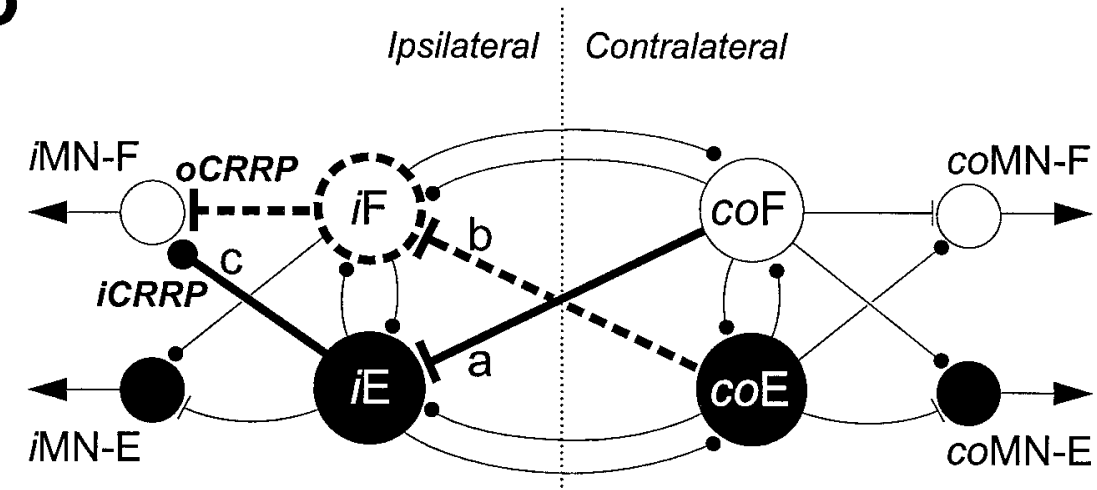

C

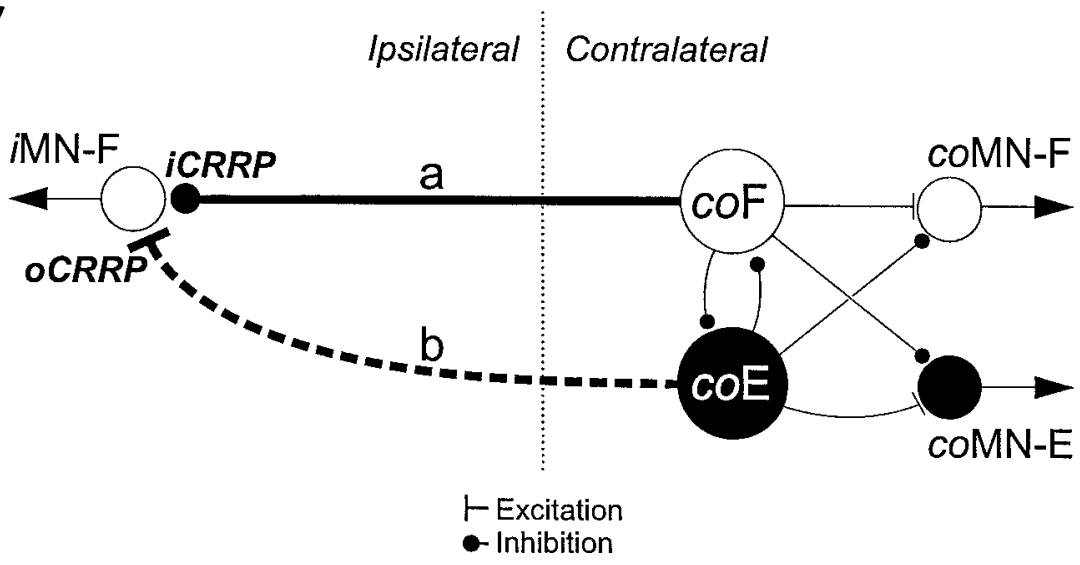

Figure 9. Three of the possible organizations of the pathways involved in the rhythmic synaptic input to ipsilateral flexor-related motoneurons $(i M N$ $F$ ), during activation of the contralateral central pattern generator (hemi-CPG). In $A-C$, the contralateral hemi-CPG is shown as the circuitry driving contralateral flexor-related activity, lumped together into a single burst generator $(c o F)$ and connected by mutual inhibition to a single burst generator driving extension $(c o E)$. In $A$, an indirect pathway (thick solid lines) conveys the iCRRP; a glutamatergic projection $(a)$ extends from the $c o F$ to ipsilateral, glycinergic relay neurons $(r)$, which in turn directly inhibit $(c)$ the ipsilateral flexor-related motoneurons $(i M N-F)$. In $B$, the pathways mediating the iCRRP are also indirect but are now integrated in the ipsilateral extensor burst generator. In $C$, the iCRRP is mediated by a direct, monosynaptic inhibitory connection $(a)$ from the contralateral flexor burst generator. The pathway $(A-C$, thick stippled lines) mediating the presumably excitatory oCRRP may be separate from $(A, C)$ but could also be integrated $(B)$ in the ipsilateral flexor burst generator $(i F)$. In $A-C$, the connections $a$ and $b$ may be polysynaptic, although for simplicity they have been shown here as monosynaptic. that the iCRRP exerts its inhibitory effect at least partly via a similar shunting effect.

The iCRRP was mediated by glycine, because strychnine generally blocked it. Why strychnine was not $100 \%$ effective remains to be investigated. Strychnine promoted bursting in one preparation (compare Cowley and Schmidt, 1995; Bracci et al., 1996) and may have weakly activated the ipsilateral rhythm generator, giving rise to a rhythmic depolarizing input to motoneurons, which compensated for an actual block of the iCRRP. Alternatively, in some motoneurons the iCRRP could be mediated by strychnine-resistant glycine receptors (Wu et al., 1995). Finally, GABA perhaps contributed to the iCRRP, because bicuculline was not completely without effect.
Functional considerations

The large majority of the L1-L3 motoneurons included in this study were flexor-related. Thus, during bilateral rhythmicity, they were excited in phase with the bursts in the corresponding ipsilateral ventral roots, shown previously to be active with flexor muscles (Kiehn and Kjaerulff, 1996). In addition, they also received a chloride-dependent inhibitory input out of phase with the ipsilateral burst. A biphasic drive has been described previously in the rat (Cazalets et al., 1996) and in other vertebrates (Russell and Wallén, 1983; Orsal et al., 1986; Robertson and Stein, 1988). Because left-right burst alternation is the normal pattern during bilateral rhythm, inhibition out of phase with the ipsilateral burst 
corresponds to inhibition in phase with the contralateral burst. This matches the characteristics of the iCRRP, and it therefore would seem to be functionally relevant if the iCRRP-related pathways indeed operate during normal locomotion.

\section{Possible organizations of the pathways mediating the iCRRP}

We have shown that glutamate receptor antagonists in some motoneurons block the iCRRP if applied ipsilaterally with respect to the recorded flexor-related motoneurons. The simplest interpretation of this result is that the contralateral rhythm generator, via a crossed glutamatergic pathway (Fig. 9A, connection $a$ ), phasically excites ipsilateral glycinergic relay interneurons (Fig. $9 A, r)$, which project locally to the flexor-related motoneurons (Fig. 9A, $i M N-F$ ). The more precise location of these putative relay neurons and whether they belong to any of the known mammalian types of spinal interneurons (e.g., Ia interneurons; see Baldissera et al., 1981) remain to be investigated. Among the neuronal classes usually incorporated in computer models simulating locomotion in simpler vertebrates, none exactly corresponds to the relay neurons. Thus, in the proposed circuitry controlling lamprey locomotion (for review, see Grillner and Matsushima, 1991) the only immediate sources of motoneuron inhibition are glycinergic CC interneurons (Buchanan, 1982). However, these neurons are not located on the same side as the motoneurons receiving the inhibition but instead are located contralaterally. Interestingly, a class of small glycinergic interneurons that monosynaptically inhibit ipsilateral motoneurons has been described in the lamprey (Buchanan and Grillner, 1988). These cells could correspond to the relay neurons in the rat. During swimming in another simple vertebrate, the Xenopus embryo, the only established spinal source of phasic inhibition in the interval between spiking is a group of glycinergic commissural interneurons that are analogous to lamprey CC interneurons (Roberts et al., 1986). Furthermore, it has been specifically argued that relay neurons mediating crossed inhibition are unlikely to be present in Xenopus (Soffe and Roberts, 1982).

In Figure $9 A$, the inhibitory putative relay neurons are considered separate from other locomotor-related circuitry on the ipsilateral side. However, it is possible that the "relay" neurons, besides receiving excitation from the contralateral hemi-CPG, are also members of the ipsilateral hemi-CPG (Fig. 9B). Specifically, they might provide part of the inhibitory output (Fig. 9B, connection $c$ ) from the ipsilateral extensor burst generator (Fig. $9 B, i E)$ to the flexor-related motoneurons during bilateral rhythmicity. Note that this scheme implies that the ipsilateral extensor burst generator receives an excitatory drive (Fig. 9B, connection a) from the contralateral flexor burst generator. The idea that some interneurons may be "shared" by the hemi-CPGs on both sides, in a scheme similar to Figure $9 B$, has originated earlier from experiments involving fictive hindlimb scratching in the turtle (Stein et al., 1995). More work is necessary to establish which of the schemes in Figure 9, $A$ and $B$, most closely represents the actual organization of the indirect iCRRP-related pathways.

In some motoneurons, the iCRRP was not effectively blocked by ipsilateral glutamate receptor antagonists. The varying effect of these antagonists suggests a heterogeneity in the organization of CRRP-related pathways to different motoneurons. We suggest that for those cells in which glutamate receptor antagonists were not efficient, a part of the iCRRP originated via a direct crossed projection from contralateral glycinergic interneurons (Fig. 9C, connection $a$ ). This arrangement is very similar to the one established in simpler vertebrates. In the cat, retrograde transneuronal labeling with horseradish peroxidase has identified a group of possibly inhibitory last-order interneurons in lamina VIII, which project to contralateral motoneurons (Harrison et al., 1986). A roughly homologous neuronal class might contribute to a directly mediated iCRRP in the rat.

\section{The oCRRP}

Our pharmacological evidence, although preliminary, suggests that the oCRRP, i.e., the depolarization occurring out of phase with the burst in the contralateral ventral root, represents an excitatory, glutamatergic drive. Because of left-right burst alternation, this excitation matches the excitatory drive in phase with the ipsilateral burst that the flexor-related motoneurons receive during bilateral rhythmicity. Therefore, like the iCRRP, the oCRRP appears to make functional sense. However, further studies are clearly needed to establish this firmly.

The low number of motoneurons with an oCRRP, compared with motoneurons with an iCRRP, may reflect that the output from the contralateral extensor burst generator (Fig. 9A-C, $c o E$ ), which we suggest is the primary origin of the oCRRP, is typically absent or is relatively weak compared with the output from the contralateral flexor burst generator. Alternatively, the pathways mediating the oCRRP (Fig. 9A-C, thick stippled lines) may not reliably transmit the excitatory drive from the contralateral hemiCPG to the ipsilateral flexor-related motoneurons. Finally, it should be noted that the relative paucity of oCRRPs is not necessarily general but could be specific for the population of rostral lumbar motoneurons from which we recorded.

\section{Conclusion}

In summary, we suggest that during mammalian locomotion the hemi-CPGs contribute to the normal activity pattern of contralateral flexor-related motoneurons, primarily by generating a crossed rhythmic inhibition, which adds to the inhibition in the silent phase of the activity of these neurons. Furthermore, this crossed inhibitory input is typically mediated by pathways organized in a more complex way than in simpler vertebrates, although similarities in the organization of left-right coordinating pathways between these animals and the rat clearly exist. The longitudinal split-bath preparation should be useful also to investigate the crossed input to locomotor-related neurons other than motoneurons.

\section{REFERENCES}

Baldissera F, Hultborn H, Illert M (1981) Integration in spinal neuronal systems. In: Handbook of physiology. The nervous system, Vol II, Motor control, Pt 1 (Brooks VB, ed), pp 509-595. Bethesda, MD: American Physiological Society.

Bekoff A, Lau B (1980) Interlimb coordination in 20-day-old rat fetuses. J Exp Zool 214:173-175.

Bekoff A, Trainer W (1979) The development of interlimb co-ordination during swimming in postnatal rats. J Exp Biol 83:1-11.

Bracci E, Ballerini L, Nistri A (1996) Localization of rhythmogenic networks responsible for spontaneous bursts induced by strychnine and bicuculline in the rat isolated spinal cord. J Neurosci 16:7063-7076.

Buchanan JT (1982) Identification of interneurons with contralateral caudal axons in the lamprey spinal cord: synaptic interactions and morphology. J Neurosci 47:961-975.

Buchanan JT, Grillner S (1988) A new class of small inhibitory interneurons in the lamprey spinal cord. Brain Res 438:404-407.

Cazalets JR, Menard I, Crémieux J, Clarac F (1990) Variability as a characteristic of immature motor systems: an electromyographic study of swimming in the newborn rat. Behav Brain Res 40:215-225.

Cazalets JR, Borde M, Clarac F (1995) Localization and organization of the central pattern generator for hindlimb locomotion in newborn rats. J Neurosci 15:4943-4951.

Cazalets JR, Borde M, Clarac F (1996) The synaptic drive from the 
spinal locomotor network to motoneurons in the newborn rat. J Neurosci 16:298-306.

Coombs JS, Eccles JC, Fatt P (1955) The specific ionic conductance and the ionic movements across the motoneuronal membrane that produce the inhibitory post-synaptic potential. J Physiol (Lond) 130:326-373.

Cowley KC, Schmidt BJ (1995) Effects of inhibitory amino acid antagonists on reciprocal inhibitory interactions during rhythmic motor activity in the in vitro neonatal rat spinal cord. J Neurophysiol 74:1109-1117.

Cowley KC, Schmidt BJ (1997) Regional distribution of the locomotor pattern-generating network in the neonatal rat spinal cord. J Neurophysiol 77:247-259.

Dale N (1986) Excitatory synaptic drive for swimming mediated by amino acid receptors in the lamprey. J Neurosci 6:2662-2675.

Dale N (1995) Experimentally derived model for the locomotor pattern generator in the Xenopus embryo. J Physiol (Lond) 489:489-510.

Douglas JR, Noga BR, Jordan LM (1993) The effects of intrathecal administration of excitatory amino acid agonists and antagonists on the initiation of locomotion in the adult cat. J Neurosci 13:990-1000.

Gao BX, Ziskind-Conhaim L (1995) Development of glycine- and GABA-gated currents in rat spinal motoneurons. J Neurophysiol $74: 113-121$.

Grillner S (1981) Control of locomotion in bipeds, tetrapods and fish. In: Handbook of physiology, Sec 2: the nervous system (Brookhardt JM, Mountacastle VB, eds), pp 1179-1236, Bethesda, MD: American Physiological Society.

Grillner S, Matsushima T (1991) The neural network underlying locomotion in lamprey - synaptic and cellular mechanisms. Neuron 7:1-15.

Harrison PJ, Jankowska E, Zytnicki D (1986) Lamina VIII interneurones interposed in crossed reflex pathways in the cat. J Physiol (Lond) 371:147-166.

Iizuka M, Kiehn O, Kudo N (1997) Development in neonatal rats of the sensory resetting of the locomotor rhythm induced by NMDA and 5-HT. Exp Brain Res 114:193-204.

Jahr CE, Yoshioka K (1986) Ia afferent excitation of motoneurones in the in vitro new-born rat spinal cord is selectively antagonized by kynurenate. J Physiol (Lond) 370:515-530.

Jiang ZJ, Shen E, Dun NJ (1990) Excitatory and inhibitory transmission from dorsal root afferents to neonate rat motorneurons in vitro. Brain Res 235:110-118.

Kiehn O, Kjaerulff O (1996) Spatiotemporal characteristics of 5-HT and dopamine-induced rhythmic hindlimb activity in the in vitro neonatal rat. J Neurophysiol 75:1472-1482.

Kiehn O, Iizuka M, Kudo N (1992) Resetting from low threshold afferents of $N$-methyl-D-aspartate-induced locomotor rhythm in the isolated spinal cord-hindlimb preparation from newborn rats. Neurosci Lett 148:43-46.

Kjaerulff O, Kiehn O (1996) Distribution of networks generating and coordinating locomotor activity in the neonatal rat spinal cord in vitro. A lesion study. J Neurosci 16:5777-5794.

Kjaerulff O, Barajon I, Kiehn O (1994) Sulphorhodamine-labelled cells in the neonatal rat spinal cord following chemically induced locomotor activity in vitro. J Physiol (Lond) 478:265-273.

Kremer E, Lev-Tov A (1997) Localization of the spinal network associated with generation of hindlimb locomotion in the neonatal rat and organization of its transverse coupling system. J Neurophysiol 77:1155-1170.

Kudo N, Yamada T (1987) N-Methyl-D,L-aspartate-induced locomotor activity in a spinal cord-hindlimb muscles preparation of the newborn rat studied in vitro. Neurosci Lett 75:43-48.
Nicoll RA, Malenka RC, Kauer JA (1990) Functional comparison of neurotransmitter receptor subtypes in mammalian central nervous system. Physiol Rev 70:513-565.

Nicolopoulos-Stournaras S, Iles JF (1983) Motor neuron columns in the lumbar spinal cord of the rat. J Comp Neurol 217:75-85.

Orsal D, Perret C, Cabelguen JM (1986) Evidence of rhythmic inhibitory synaptic influences in hindlimb motoneurons during fictive locomotion in the thalamic cat. Exp Brain Res 64:217-224.

Ozaki S, Yamada T, Iizuka M, Nishimaru H, Kudo N (1996) Development of locomotor activity induced by NMDA receptor activation in the lumbar spinal cord of the rat fetus studied in vitro. Dev Brain Res 97:118-125.

Pinco M, Lev-Tov A (1993) Synaptic Excitation of $\alpha$-motoneurons by dorsal root afferents in the neonatal rat spinal cord. J Neurophysiol 70:406-417.

Roberts A, Soffe SR, Clarke JDW, Dale N (1983) Initiation and control of swimming in amphibian embryos. Symp Soc Exp Biol 37:261-284.

Roberts A, Soffe SR, Dale N (1986) Spinal interneurones and swimming in frog embryos. In: Neurobiology of vertebrate locomotion (Grillner S, Stein PSG, Stuart DG, Forssberg H, Herman RM, eds), pp 279-306. New York: Macmillan.

Roberts A, Tunstall M, Wolf E (1995) Properties of networks controlling locomotion in a simple vertebrate and significance of voltagedependency of NMDA channels: a simulation study of rhythm generation sustained by positive feedback. J Neurophysiol 73:485-495.

Robertson GA, Stein PSG (1988) Synaptic control of hindlimb motoneurons during three forms of the fictive scratch reflex in the turtle. J Physiol (Lond) 404:101-128.

Rossignol S (1996) Neural control of stereotypic limb movements. In: Handbook of physiology, Sec 12, Exercise: regulation and integration in multiple systems (Rowell LB, Shepherd JT, eds), pp 173-216. Bethesda, MD: American Physiological Society.

Russell DF, Wallén P (1983) On the control of myotomal motoneurones during "fictive swimming" in the lamprey spinal cord in vitro. Acta Physiol Scand 117:161-170.

Smith JC, Feldman JL (1987) In vitro brainstem-spinal cord preparations for study of motor systems for mammalian respiration and locomotion. J Neurosci Methods 21:321-333.

Soffe SR, Roberts A (1982) Tonic and phasic input to spinal cord motoneurons during fictive locomotion in frog embryos. J Neurophysiol 48:1279-1288.

Sqalli-Houssaini Y, Cazalets JR, Clarac F (1993) Oscillatory properties of the central pattern generator for locomotion in neonatal rats. J Neurophysiol 70:803-813.

Stein PSG, Victor JC, Field EC, Currie SN (1995) Bilateral control of hindlimb scratching in the spinal turtle: contralateral spinal circuitry contributes to the normal ipsilateral motor pattern of fictive rostral scratching. J Neurosci 15:4343-4355.

Wallén P, Ekeberg Ö, Lansner A, Brodin L, Tråvén H, Grillner S (1992) A computer-based model for realistic simulations of neural networks. II. The segmental network generating locomotor rhythmicity in the lamprey. J Neurophysiol 68:1939-1950.

Westerga J, Gramsbergen A (1990) The development of locomotion in the rat. Dev Brain Res 57:163-174.

Wu SY, Miyazaki T, Dun NJ (1995) Glycine induces two distinct membrane currents in neonatal rat sympathetic preganglionergic neurons. J Physiol (Lond) 483:385-396.

Wu W, Ziskind-Conhaim L, Sweet MA (1992) Early development of glycine- and GABA-mediated synapses in rat spinal cord. J Neurosci 12:3935-3945. 